\title{
Long-term cattle grazing shifts the ecological state of forest soils
}

\author{
Willem Proesmans ${ }^{1}$, Christopher Andrews ${ }^{2}$, Alan Gray ${ }^{3}$, Rob Griffiths ${ }^{3}$, Keith Aidan ${ }^{4}$, Uffe \\ Neilsen $^{5}$, David J Spurgeon ${ }^{3}$, Richard Pywell ${ }^{6}$, Bridget Emmett ${ }^{7}$, and Adam Vanbergen ${ }^{8}$ \\ ${ }^{1}$ INRA Dijon Research Centre \\ ${ }^{2}$ UK Centre for Ecology \& Hydrology \\ ${ }^{3}$ Centre for Ecology and Hydrology \\ ${ }^{4}$ University College Dublin \\ ${ }^{5}$ Western Sydney University \\ ${ }^{6}$ Centre for Ecology \& Hydrology \\ ${ }^{7}$ UK Centre for Ecology and Hydrology, Environment Centre Wales \\ ${ }^{8}$ INRA Dijon
}

January 18, 2022

\begin{abstract}
1. Cattle grazing profoundly affects abiotic and biotic characteristics of ecosystems. While most research has been performed on grasslands, the effect of large managed ungulates on forest ecosystems has largely been neglected. 2. Compared to a baseline semi-natural state, we investigated how long-term cattle grazing of birch forest patches affected the abiotic state and the ecological community (microbes and invertebrates) of the soil subsystem. 3. Grazing strongly modified the soil abiotic environment by increasing phosphorus content, $\mathrm{pH}$ and bulk density, while reducing the C:N ratio. The reduced C:N-ratio was strongly associated with a lower microbial biomass, mainly caused by a reduction of fungal biomass. This was linked to a decrease in fungivorous nematode abundance and the nematode channel index, indicating a relative uplift in the importance of the bacterial energy-channel in the nematode assemblages. 4. Cattle grazing highly modified invertebrate community composition producing distinct assemblages from the semi-natural situation. Richness and abundance of microarthropods was consistently reduced by grazing (excepting collembolan richness) and grazing-associated changes in soil pH, Olsen $\mathrm{P}$ and reduced soil pore volume (bulk density) limiting niche space and refuge from physical disturbance. Anecic earthworm species predominated in grazed patches, but were absent from ungrazed forest, and may benefit from manure inputs, while their deep vertical burrowing behaviour protects them from physical disturbance. 5. Perturbation of birch forest habitat by long-term ungulate grazing profoundly modified soil biodiversity, either directly through increased physical disturbance and manure input or indirectly by modifying soil abiotic conditions. Comparative analyses revealed the ecosystem engineering potential of large ungulate grazers in forest systems through major shifts in the composition and structure of microbial and invertebrate assemblages, including the potential for reduced energy flow through the fungal decomposition pathway. The precise consequences for trophic interactions and biodiversity-ecosystem function relationships remains to be established, however.
\end{abstract}

\section{Hosted file}

Birch_grazing_Proesmans_et_al_EE.doc available at https://authorea.com/users/455888/articles/ 553127-long-term-cattle-grazing-shifts-the-ecological-state-of-forest-soils 